\title{
COMUNIDADES VIRTUAIS - UM NOVO ESPAÇO DE APRENDIZAGEM
}

\author{
Eunice Maria Mussoi \\ Prof ${ }^{\mathrm{a}}$. MSc.Santa Maria; aluna Especial PGIE \\ emmussoi@yahoo.com.br \\ Maria Lucia Pozzatti Flores \\ Prof $^{\text {a }}$. MSc. Ulbra-SM; aluna Especial PGIE \\ mlflores@terra.com.br \\ mlflores1@gmail.com \\ Prof $^{a}$. Dr ${ }^{\mathrm{a}}$. Patricia Alejandra Behar \\ PGIE-PPGEdu/UFRGS \\ pbehar@terra.com.br
}

\section{RESUMO}

Este artigo busca fazer uma reconstrução teórica do conceito de comunidade virtual (CV) e de comunidade virtual de aprendizagem (CVA). As comunidades virtuais são definidas como redes virtuais de comunicação interativa, organizadas em torno de interesses compartilhados. Já as comunidades virtuais de aprendizagem são constituídas a partir de interesses comuns de conhecimento estabelecidos em um processo cooperativo. A interação entre os participantes de uma comunidade virtual de aprendizagem cria espaços que privilegiem a co-construção do conhecimento criando, assim, uma nova concepção de aprendizagem.

Palavras-Chaves: Comunidade Virtual. Comunidade Virtual de Aprendizagem. nteração. Cooperação.

\section{ABSTRACT}

This article presents an reconstruction for the concept of virtual community and virtual learning community, in an theoretical view-point. Virtual communities are defined as virtual nets of interactive communication, organized around shared interests. In the ther side, virtual learning communities are constituted from common interests of knowledge, established in a cooperative process. The interation between the partners of a virtual learning community will create spaces that privilege the co-construction of the nowledge, thus creating a new conception of learning.

Word-Keys: Virtual community. Virtual Learning Community. Interation. Cooperation.

\section{1-INTRODUÇÃO}

Ao estudar a origem histórica das primeiras civilizações, percebe-se que os pesquisadores da área indicam que inicialmente o ser humano era nômade, vivia da caça, pesca e coleta dos produtos que a natureza lhe oferecia. Para garantir sua sobrevivência, com o passar dos anos, o ser humano aprendeu a se organizar em grupos e se fixou, constituindo as primeiras comunidades, que por sua vez deram origem às primeiras civilizações. 
As primeiras comunidades surgiram para garantir a vida, a auto-preservação dos indivíduos. Para sua permanência, ao longo do tempo, estes grupos humanos estabeleceram formas de se expressar, valores morais e culturais compatíveis com cada época. A escrita, como forma de comunicação, surgiu para preservar e perpetuar a cultura e os valores do ser humano. $\mathrm{O}$ modo de comunicação define a identidade do indivíduo, do grupo ou de uma nação.

Com o passar dos anos, com os avanços tecnológicos, com a globalização, surgem novas formas de comunicação e transmissão cultural, como por exemplo: o jornal, os livros, o rádio, as revistas, a televisão,o computador, os satélites, a Internet e o e-mail.

A década de 80 foi caracterizada pela popularização do computador pessoal. Com o advento da Internet e suas ferramentas de comunicação e interação, o computador pessoal foi substituído pelo computador coletivo, interligado através de um sistema de rede, assim se estabelece a era da comunicação digital. Estas novas tecnologias facilitaram a constituição de grupos de sujeitos ligados por vínculos não formalizados, os quais tinham características comuns, formando as comunidades virtuais.

Estes grupos de pessoas interconectadas, utilizando-se do computador e da Internet como ferramentas de comunicação e interação, acabaram por constituírem as primeiras comunidades virtuais.

Com essa perspectiva, este artigo aborda os conceitos de comunidade virtual e a comunidade virtual na perspectiva da aprendizagem. Busca, também, respostas a algumas inquietações, como: Será a comunidade virtual de aprendizagem um novo espaço de aprendizagem? Será a Comunidade Virtual de Aprendizagem uma prática de construção de conhecimento mais eficiente que a sala de aula tradicional?

Este artigo foi escrito a partir das atividades propostas pela Oficina das Comunidades Virtuais de Aprendizagem (COMVIA), na disciplina de Oficinas Virtuais de Aprendizagem do curso de doutorado em Informática na Educação (PGIE), na Universidade Federal do Rio Grande do Sul1.

\section{2- COMUNIDADES VIRTUAIS}

Howard Rheingold foi o primeiro autor a difundir o conceito de comunidade virtual, em 1993. Ele define a comunidade virtual como uma agregação cultural formada pelo encontro sistemático de um grupo de pessoas no ciberespaço. Este tipo de comunidade é caracterizada pela co-atuação de seus participantes, os quais compartilham valores, interesses, metas e posturas de apoio mútuo, através de interações no universo on-line. Comunidades virtuais são redes eletrônicas de comunicação interativa auto-definida, organizadas em torno de um interesse ou finalidade compartilhada. Esse novo sistema e comunicação pode abarcar e integrar todas as formas de expressão, bem como a diversidade de interesses, valores e imaginações, inclusive a expressão de conflitos, isso tudo devido a sua diversificação, multimodalidade e versatilidade (Schlemmer, 2005).

Palacios (1998) apud Sampaio - Ralha (2000) enumera os elementos que caracterizariam a comunidade: "o sentimento de pertencimento, a territorialidade, a permanência, a ligação entre o sentimento de comunidade, caráter corporativo e emergência de um projeto comum, e a existência de formas próprias de comunicação". O sentimento de pertencimento, ou "pertença", seria a noção de que o indivíduo é parte do todo, coopera para uma finalidade comum com os demais membros (caráter corporativo, sentimento de

1 A disciplina foi realizada durante o primeiro semestre de 2007. Maiores informações sobre a disciplina encontram-se disponíveis em www.ufrgs.br/faced/pos/ofertacurricular/sum20071/Patricia SA.doc 
comunidade e projeto comum); a territorialidade, o locus da comunidade; a permanência, condição essencial para o estabelecimento das relações sociais.

Para Murray Turoff pesquisador americano, idealizador do sistema de intercâmbio de informação eletrônica (EIES), considerado o ponto de partida das atuais comunidades on-line, prenunciava que a conferência por computador poderia fornecer aos grupos humanos uma forma de exercitarem a capacidade de 'inteligência coletiva'. Segundo ele, um grupo bem sucedido exibirá um grau de inteligência maior em relação a qualquer um de seus membros (Turoff apud Rheingold, 1996). Estava lançada assim a idéia de que a interconexão de computadores poderia dar nascimento a uma nova forma de atividade coletiva, centrada na difusão e troca de informações, conhecimentos, interesses, etc (Murray Turoff ,1976 apud Costa, 2005).

Em sua obra Cibercultura, Pierre Lévy (1999), apresenta a criação de comunidades virtuais como um dos três princípios que orientaram o crescimento inicial do ciberespaço.

Os outros dois princípios são a interconexão e a inteligência coletiva. A "interconexão constitui a humanidade em um contínuo sem fronteiras", todos no mesmo "banho de comunicação interativa". Ela "tece um universal por contato" no ciberespaço. Um universal heterogêneo que cresce e expande filamentos, sem totalidade. Interconexão, comunidade virtual e inteligência coletiva são aspectos de um universal por contato. Ainda, segundo o autor, a comunidade virtual é construída sobre afinidades de interesses, de conhecimentos, sobre projetos mútuos, em um processo de cooperação ou de troca, independente das proximidades geográficas e das filiações institucionais. A moral implícita de uma comunidade virtual é a da reciprocidade. Cabe a ela estabelecer as normas de convivência, a sua netiqueta e não encorajar o anonimato. Assim como nas comunidades presenciais, podem surgir afinidades, amizades, conflitos, manipulações e enganações.

As comunidades virtuais exploram novas formas de opinião pública, nelas ocorrem contatos e interações de todos os tipos. Trata-se de um coletivo mais ou menos permanente que se organiza, interconectado, por meio do novo correio eletrônico mundial.

"Comunidade atual seria a expressão muito mais adequada para descrever os fenômenos de comunicação coletiva no ciberespaço do que comunidade virtual"(Lévy, 1999).

As comunidades virtuais se constituem de grupos de pessoas interconectadas em busca da inteligência coletiva, ela é uma inteligência coletiva em potencial. Um grupo humano se interessa em constituir-se como comunidade virtual para aproximar-se do ideal do coletivo inteligente, mais imaginativo, mais capaz de aprender e inventar. A virtualização ou desterritorialização das comunidades no ciberespaço são condições para haver inteligência coletiva em grande escala. A inteligência coletiva é o terceiro princípio da cibercultura. O ciberespaço é a ferramenta de organização de comunidades de todos os tipos, o melhor uso do ciberespaço pode ser alcançado ao se colocar em sinergia os saberes, as imaginações e as energias espirituais daqueles de estão conectados a ele. A cibercultura é a expressão da aspiração de construção de um laço social, fundado sobre a reunião em torno de centros de interesses comuns, no compartilhamento de informações, na cooperação e nos processos de colaboração.

Com uma visão mais objetiva, Palloff e Pratt (2004) citam Preece (2000) ao afirmar que "comunidade on-line consiste em pessoas, em um objeto, em políticas comuns e nos sistemas de computador. As pessoas interagem socialmente quando tentam satisfazer suas próprias necessidades ou desempenhar papéis especiais, como os de líder ou de moderador". 
Os líderes e moderadores têm a função de animadores de comunidades virtuais. Trata-se de uma função muito importante, pois o animador de comunidades é o "o agente da ação social, que promove a inter-relação, instiga à participação, traz idéias e temas a serem debatidos. É dele a "função" de agitar, promover a comunicação e a interação entre as partes, no processo de comunicação" (Sampaio-Ralha, 2000).

Os serviços de $\mathrm{BBS}_{2}$ e chat (como o IRC), constituem pontos de encontro on-line, têm contribuído para a formação de comunidades virtuais. O IRC (Internet Relay Chat) pode reunir pessoas de diversos países e culturas diferentes. Os participantes são bastante tolerantes com a dificuldade de linguagem, como é o caso da língua inglesa. A dificuldade de se expressar pela escrita, pode ser superada pelo uso de imagens, de emotions, e de algumas abreviações. Toda comunidade virtual tem suas regras de conduta, que emergem naturalmente para preservar seus usuários e o objetivo da comunidade.

Para Primo (1997) "os usuários desses serviços se conectam habitualmente aos chat rooms, ou salas de encontros virtuais, que tem por título assuntos que lhes são relevantes. É nesse convívio que desenvolvem suas personas, que desenvolvem um senso comunitário e que fazem e desfazem amizades". Através da tela do monitor as pessoas trocam experiências, discutem, desenvolvem amizades e amores, flertam, jogam, muitas relações virtuais se tornam reais. "Um usuário de um chat fará parte da comunidade enquanto se conectar habitualmente a ele".

A diversidade de pessoas, desde adolescentes até adultos, estudantes ou não, profissionais, aposentados, idosos utilizam-se cada vez mais destas ferramentas de interação. Os assuntos e a motivação variam, conforme a faixa etária e podem ser: música, cinema, fofocas, educação, economia, esportes, tratamentos alternativos, lazer, turismo, ecologia, sexo, etc, são tão diversos quanto à comunidade.

Em um sistema de chat o usuário tem que escolher um nick, ou seja, um apelido curto que identificará a autoria das mensagens enviadas. A escolha do apelido é levada a sério, pois ele representa o usuário. A pessoa acaba desenvolvendo um estilo próprio de comunicação que o caracteriza. Quando o nick e a abordagem adotados pelo usuário não dão certo, é possível efetuar a troca. Virtualmente será uma nova pessoa, uma nova chance para tornar-se reconhecido e valorizado no grupo virtual.

Como a Internet é muito dinâmica, a sua evolução tem nos proporcionado novas ferramentas que promovem a interação e participação, através de comunidades. Conforme Primo (2006) podemos considerar que inicialmente, na Internet os sites eram trabalhados como unidades isoladas, dando-se ênfase na publicação ou emissão de informações, conforme o modelo transmissionista. Com o advento da web 2.0, a segunda geração da Internet, passa-se para uma estrutura integrada de funcionalidades e conteúdo, promovendo a interação e participação, segundo o modelo interacionista. Surgem o Orkut3, os Blogs4 com comentários e sistema de assinaturas, o Flickr5, o del.icio.us6 e Technorati7, por

\footnotetext{
2 Bulletim Board Sistem; originado a partir dos usuários da rede Usenet (uma rede acadêmica de equipamentos com Sistema Operacional UNIX, conectados através de linhas discadas via UUCP), atualmente está amplamente difundido pela Internet.

3 www.orkut-brasil.com/

4 www.blogs.com.br/

5 www.flickr.com/

6 del.icio.us/

7 technorati.com/
} 
exemplo, as enciclopédias escritas colaborativamente, como a Wikipédias e sites de webjornalismo participativo, como Ohmy News9, Wikinews10 e Slashdot11.

Portanto, percebe-se que existe uma diversidade de ferramentas que propiciam a constituição de comunidades on-line. O tempo de uso, que pode ser permanente ou temporário, irá determinar a duração da comunidade virtual. Quando as comunidades virtuais são constituídas a partir de interesses comuns de construção de conhecimento são consideradas de aprendizagem. Na próxima seção será abordado o processo da aprendizagem e, após, a comunidade virtual de aprendizagem.

\section{2-O PROCESSO DA APRENDIZAGEM}

Ao tratar de comunidades virtuais de aprendizagem e, portanto, da aprendizagem, as autoras entendem que termos como "aprendizagem" e "processo de ensino e aprendizagem" devam ser abordados. Tendo como base teórica a obra de Becker (1993), passar-se-á a abordá-los no texto que segue.

O processo de ensino e aprendizagem pode ser definido como o modo que o ser humano adquire novo conhecimento, desenvolve competências e muda o comportamento.

Este processo baseia-se em metodologias, desenvolvidas em diferentes concepções epistemológicas. As concepções abordam as diferentes compreensões sobre a aquisição do conhecimento, delas resultam diferentes modelos educacionais e práticas pedagógicas.

Para a concepção apriorista, o conhecimento está a priori, isto é, a origem do conhecimento está no próprio sujeito, suas estruturas vêm programadas na bagagem hereditária, predeterminada. O conhecimento é entendido como algo exclusivo do sujeito, sem a participação do meio, e precisa ser despertado no aluno (Becker, 1993).

$\mathrm{Na}$ concepção empirista o objeto é a base do conhecimento, sendo que este precisa ser transmitido. O professor é o transmissor do conhecimento. O aluno é entendido como uma "tábula rasa", passivo, um receptor.

Já na concepção interacionista, o conhecimento não está no sujeito, nem no objeto, mas sim na interação, resultando da ação do sujeito. O sujeito está em processo de aprendizagem, construindo e reconstruindo suas próprias estruturas. Busca-se romper com a hierarquia das relações professor e aluno, que juntos dialogam e estabelecem regras. O professor oportuniza o acesso às informações, é mediador, problematizador, instigador, orientador e articulador do processo. É a ação do sujeito que realmente importa no processo de aprendizagem. Podemos afirmar que a aprendizagem pode resultar das interações entre sujeitos, em um meio físico e social.

Sendo assim, ao pensar-se nas tecnologias da informática e metodologias para o ensino e aprendizagem on-line, o computador pode ser usado de diversas formas, refletindo os teóricos que embasam a proposta educativa. Quando usado como "máquina de ensinar", instrução programada ou ensino a distância corresponderá à concepção empirista. Porém, quando usado na perspectiva de interação e construção de conhecimento, podendo utilizarse de ambientes ou comunidades virtuais de aprendizagem, corresponderá à concepção interacionista.

8 pt.wikipedia.org/

9 english.ohmynews.com/

10 pt.wikinews.org/

11 slashdot.org/ 


\section{3- A COMUNIDADE VIRTUAL NA PERSPECTIVA DA APRENDIZAGEM}

As comunidades virtuais de aprendizagem realizam comunicações interativas, onde as normas, os valores e os comportamentos são definidos na própria comunidade. A aprendizagem é cooperativa e todos os sujeitos têm o mesmo direito de participação. $\mathrm{O}$ sujeito assume o papel ativo na construção do seu conhecimento de acordo com tema da comunidade e o educador tem o papel de orientador. Para Lévy (1999) "a direção mais promissora, que por sinal traduz a perspectiva da inteligência coletiva no domínio educativo, é a da aprendizagem cooperativa”.

As comunidades virtuais de aprendizagem, conforme Passarelli (2003) foram gestadas no espaço midiático da Internet e representam novas possibilidades para o processo de ensino e aprendizagem, tanto no âmbito da educação formal (escolas tradicionais) como no da educação não-formal (educação comunitária, educação para a vida).

Considera-se comunidade virtual de aprendizagem redes eletrônicas de comunicação interativa, organizada em torno de um projeto mútuo. Elas são constituídas a partir de interesses comuns de conhecimento estabelecidos em um processo cooperativo.

Para haver aprendizagem em uma comunidade on-line, Palloff e Pratt (1999) propõem seis palavras-chave: honestidade, correspondência, pertinência, respeito, franqueza e autonomia. Para Palloff e Pratt (2004) uma comunidade virtual on-line consiste em pessoas, em um objetivo, em políticas comuns e nos sistemas de computador. As pessoas interagem socialmente, tentando satisfazer suas próprias necessidades ou o desempenho de papéis especiais (líder, moderador).

As comunidades virtuais de aprendizagem priorizam a interação social, a aprendizagem colaborativa e o trabalho cooperativo. Nesta perspectiva, a própria comunidade se legitima, por constituir-se a partir de afinidades de interesses, de conhecimentos, de projetos mútuos e valores de troca, estabelecidos no processo de cooperação.

Segundo Magdalena e Costa (2005), as Comunidades Virtuais de Aprendizagem promovem um novo modo do ser, de saber e de apreender, em que cada novo sistema de comunicação, da informação cria novos desafios, que implicam novas competências e novas formas de construir conhecimento.

Para Palloff e Pratt (1999), as especificidades das comunidades virtuais de aprendizagem seguem os seguintes pressupostos:

-Destinar-se a interesses comuns a todos os sujeitos participantes da comunidade;

-Ênfase no trabalho em equipe;

-A comunidade deve centrar sua dinâmica nos objetivos a serem alcançados

-Todos os sujeitos têm o mesmo direito de participação.

-As normas, valores e comportamentos são definidos na própria comunidade;

-O educador assume o papel de orientador e animador da comunidade;

-A aprendizagem é cooperativa/colaborativa;

-O sujeito assume o papel ativo na construção do seu conhecimento de acordo com tema da comunidade;

-Interação permanente.

Uma comunidade on-line pode se formar tendo como objetivo a aprendizagem, através do envolvimento em um curso. Assim, as pessoas envolvidas (professores, alunos, tutores, administradores,...) passam a interagir, são discutidas e negociadas as diretrizes e as regras do curso, as políticas de aprendizagem.

Neste contexto, a interação ativa, envolvendo conteúdo e comunicação social; aprendizagem colaborativa; significados construídos socialmente e evidenciados pela concordância ou questionamento, com a intenção de chegar a um acordo; 
compartilhamento de recursos entre os alunos; expressões de apoio e estímulo; vontade de avaliar criticamente o trabalho dos colegas, são os indicativos de que a comunidade on-line formou-se de fato e integrou-se ao grupo.

Palloff e Pratt (2004) afirmam que, para que haja sucesso, uma comunidade virtual de aprendizagem deve ter uma abordagem centrada no aluno. Além disso, o papel e a presença do professor, bem como o envolvimento ativo do aluno, são críticos para o êxito.

\section{4-APLICAÇÃO DAS CVAs}

As comunidades virtuais de aprendizagem estão permitindo configurar novos espaços de interação e de aprendizagem. Um interagente de qualquer ponto pode não só trocar informações, mas reconstruir significados, rearticular idéias tanto individualmente quanto coletivamente; e, assim, partilhar novos sentidos com todos os interagentes da rede.

As comunidades virtuais de aprendizagem podem ser apreciadas como ambientes no qual praticas educativas estão sendo constantemente desenvolvidas. Estas proporcionam espaço para que interações e reflexões voltadas para o processo de aprender possa se dar em diversos âmbitos. Todos os componentes da CVA são agentes deste processo, trabalhando em prol de um mesmo objetivo.

A sociabilidade e a sensação de pertencimento ao grupo, proporcionado pela comunidade virtual de aprendizagem, resultam em uma aprendizagem cada vez mais independente do espaço escolar tradicional. A tradicional concepção de sala de aula, com alunos-expectadores enfileirados diante de um professor-especialista detentor da informação, deve ser modificada tanto nos ambientes presenciais, semi-presenciais ou não presenciais. A interação, entre os participantes de uma comunidade virtual de aprendizagem, cria espaços que privilegiam a co-construção do conhecimento e, também, a consciência da ética ao interagir no conhecimento de outra pessoa. Isto significa uma nova concepção de aprendizagem.

As comunidades virtuais de aprendizagem com seus elementos técnicos e, principalmente, humanos, seu feixe de relações contido no ciberespaço com uma identidade e um contexto específico, são criadas com a intenção clara de aprendizado.

Uma mesma comunidade pode agregar diferentes estilos de aprendizagem. Muitos teóricos desenvolveram importantes pesquisas na área, como Gardner (1983), Listzinger e Osif (1993), Armstrong (1994), O’Connor (1997). Diante da diversidade de alunos que podem ser encontrados em uma comunidade de aprendizagem on-line, a expressão "nem tudo serve para todos" quando relacionada à aprendizagem, pode causar grande preocupação ao professor. Os estilos de aprendizagem podem ser definidos como os todos pelos quais se aprende. São vários os estilos de aprendizagem, sendo assim, o professor não deve adotar uma mesma abordagem. Seria um erro pensar que todo o aluno on-line tem o mesmo padrão de aprendizagem.

O professor precisa encontrar um modo de trabalho que aborde todos ou a maioria dos estilos de aprendizagem. Para Palloff e Pratt (2004) "quanto mais atenção os professores dão à formação de uma comunidade de aprendizagem on-line sólida, provavelmente mais conseguirão atender aos diferentes estilos de aprendizagem e preferências dos alunos, adultos ou jovens". As atividades propostas podem ser desenvolvidas de forma individual, ou em pares, ou professor/aluno ou em grupo. O melhor é oferecer atividades variadas. Para isso, os autores destacam a importância do uso de uma atividade colaborativa ao longo do processo, pois ela pode estimular as seis capacidades de aprendizagem apresentadas por Boud e Griffin (1987) apud Palloff e Pratt (2004): 
racional, emocional, física, metafórica e espiritual. Optar por uma "atividade colaborativa em um curso on-line é provavelmente a melhor maneira de abranger todos os estilos de aprendizagem do grupo". A colaboração ajuda ao desenvolvimento do pensamento crítico, a co-criação do conhecimento e do significado, a reflexão e a aprendizagem transformadora.

Palloff e Pratt (2004) desenvolveram algumas técnicas instrucionais para que o professor e/ou o tutor incentivem o aluno virtual assumir a responsabilidade na formação das comunidades de aprendizagem on-line.

-Abertura: compartilhar detalhes acerca do trabalho e da vida fora da escola, através do envio de apresentações pessoais e bibliografias; da criação de um espaço de interação social no curso; do incentivo ao uso judicioso do chat para a socialização, do próprio exemplo, demonstrando abertura e humor.

-Flexibilidade e humor: desenvolver a compreensão da natureza da aprendizagem online e a vontade de seguir com a turma. Estar pronto para abdicar do controle, permitindo que os alunos assumam o processo de aprendizagem; envolver os alunos em uma aprendizagem criada também por eles; orientar os alunos sobre o papel do professor e as responsabilidades dos alunos na aprendizagem on-line; dar oportunidades para a reflexão sobre o papel do professor, do aluno e do próprio curso.

-Honestidade: estar pronto para dar e receber feedback e compartilhar pensamentos e preocupações assim que apareçam. Para isso, pode-se: dar exemplo de uma comunicação aberta e honesta; orientar os alunos para que adquiram habilidades adequadas de comunicação e para que dêem e recebam um feedback substancial; orientar os alunos sobre a realidade da aprendizagem on-line; propiciar oportunidades para o feedback, tais como enviar textos para o site do curso com a expectativa de que haja retorno e enviar as avaliações das atividades colaborativas realizadas on-line.

-Desejo de ser responsável pela formação da comunidade: Todos devem assumir esta responsabilidade, integrando-se nas discussões e em outras atividades de aprendizagem.

Sugerem técnicas como alternar ou compartilhar com os alunos o papel de facilitador, por um curto espaço de tempo; alternar a liderança dos grupos pequenos; adotar o "monitor de processos" alternando entre os integrantes do grupo, seria um aluno que comente o processo e o progresso do grupo semanalmente.

-Desejo de trabalhar em conjunto: esta capacidade pode ser impulsionada ao se definir um envio mínimo de mensagens e monitorar o processo; avaliar a participação; enviar os critérios de avaliação em que estejam estabelecidos os níveis aceitáveis de participação e envio de mensagens; usar tarefas/desafios/atividades para pequenos grupos e avaliá-las em conjunto.

\section{5-CONSIDERAÇÕES FINAIS}

Neste contexto, utilizando-se do ciberespaço, é possível proporcionar a formação das comunidades virtuais de aprendizagem, junto a uma proposta de atividade fundamentada no trabalho cooperativo, com um objetivo comum entre os participantes.

As comunidades virtuais de aprendizagem permitem que seus participantes interajam entre si, trocando conhecimento, junto com o orientador e animador da comunidade. $\mathrm{Ou}$ seja, os participantes não só trocam informações entre eles, mas reconstroem significados e rearticulam idéias. Criando, assim, uma nova concepção de aprendizagem, tornando a aprendizagem mais ágil, agradável e eficiente.

As comunidades virtuais de aprendizagem usando as técnicas disponíveis na web, como criação de webfólios, páginas web, uso de blogs, ferramentas de comunicação, entre 
outros, ampliam os "espaços" de aprendizagem, proporcionando uma aprendizagem mais independente do espaço escolar tradicional.

Como os participantes/alunos têm modos diferentes de aprender, uma comunidade deve agregar diferentes estilos de aprendizagem. O melhor é oferecer atividades variadas.

Os autores consultados recomendam o uso de uma atividade colaborativa ao longo do processo de aprendizagem. A colaboração ajuda ao desenvolvimento do pensamento crítico, a co-criação do conhecimento e do significado, a reflexão e a aprendizagem transformadora.

Costa (2005) vai além, o autor propõe a transmutação do conceito de "comunidade" em redes sociais. Para ele, o conceito de redes sociais responde a uma compreensão da interação humana de modo mais amplo que o de comunidade, ampliando o horizonte em direção às redes pessoais, onde cada indivíduo que está apto a construir sua própria rede de relações, sem que essa rede possa ser definida precisamente como "comunidade".

"Uma rede de pessoas interessadas pelos mesmos temas é não só mais eficiente do que qualquer mecanismo de busca, mas do que a intermediação cultural tradicional, que sempre filtra demais, sem conhecer no detalhe as situações e necessidades de cada um" (Lévy, 2002).

Historicamente, vivencia-se uma nova formação de comunidade, advinda das novas ferramentas de comunicação. Ainda há muito a se pesquisar e aprender sobre este tema. A multidão que povoa o mundo virtual nos força a reconhecer que estamos diante de um fenômeno social e educativo. Enquanto educador busca-se diferentes maneiras de ensinar e aprender, neste novo contexto.

\section{6-BIBLIOGRAFIA}

-ARMSTRONG, T. Multiples Intelligences in the Classroom. Alexandria, Va.: Association for Supervision and Curriculum Development, 1994.

-BECKER, F. Epistemologia do professor: cotidiano da escola. Petrópolis: Vozes, 1993.

-COSTA, R. Por um novo conceito de comunidade: redes sociais, comunidades pessoais, inteligência coletiva. Interface - Comunicação, Saúde, Educação, v.9, n.17, p.235-48, mar/ago 2005.

-GARDNER, H. Frames of mind: The theory of multiple intelligences. Chicago: Basic Books, 1983.

-LÉVY, P. Cibercultura. Rio de Janeiro: Editora 34, 1999.

-LÉVY, P. Cyberdémocratie. Paris: Odile Jacob, 2002.

-LITZINGER, M.E. and OSIF, B. Accommodating Diverse Learning Styles: Designing instruction for electronic information sources. In L. Shirato (ed.), What is good instruction Now? Library Instruction for the '90s. Ann Arbor, Mich.: Pierian Press, 1993.

-MAGDALENA, B. C. e COSTA I. E. T. Novas formas de aprender: comunidades de aprendizagem. IN: Salto para o futuro / TV Escola . Disponível em <http://www.redebrasil.tv.br/salto/boletins2005/nfa/meio.htm>. Acesso em: 30 março

2007.

-O'CONNOR, T. Using Learning Styles to adapt Technology for Higher Education. 1997. Disponível em <http://indstate.edu/ctl/styles/learning.html>. Acesso em: 20 dezembro 2002

-PALLOFF, R. M. ; PRATT, K. O aluno virtual: um guia para se trabalhar com estudantes on-line. Porto Alegre: Artmed, 2004. 
Building learning communities in cyberspace - effective strategies for the online classroom. São Francisco: Jossey-Bass Publishers, 1999.

-PASSARELLI, B. Interfaces Digitais na Educação: @lucinações Consentidas. 2003. Tese (Livre Docência) Escola de Comunicações e Artes, Universidade de São Paulo, São Paulo. 57

-PRIMO, A. O aspecto relacional das interações na Web 2.0. In: XXIX Congresso Brasileiro de Ciências da Comunicação, 2006, Brasília. Anais, 2006.

. A emergência das comunidades virtuais. In: Intercom 1997 - XX

Congresso Brasileiro de Ciências da Comunicação, 1997, Santos. Anais... Santos, 1997. Disponível em <http://www.pesquisando.atraves-da.net/comunidades_virtuais.pdf>. Acesso em: 30 março 2007.

-RAPPAPORT, C. R.; FIORI W. R.; DAVIS, C. Teorias do desenvolvimento: conceitos fundamentais. São Paulo: E.P.U., 1981.

-RHEINGOLD, H. A Comunidade Virtual. Lisboa: Gradiva, 1996. . La Comunidad Virtual: Una Sociedad sin Fronteras. Gedisa Editorial.

Colección Limites de La Ciência. Barcelona, 1994.

The Virtual Community: Homesteading at the Electronic Frontier,

1993. Disponível em <http://www.rheingold.com/vc/book/> . Acesso em: 30 março 2007.

- SAMPAIO-RALHA, J. Comunidades Virtuais: Definições, origens e aplicações.

Disponível em <http://www.rau-tu.unicamp.br/nou-rau/ead/document/?down=79> Acesso em: 10 abril 2007.

- SCHLEMMER, E. Metodologias para educação a distância no contexto da formação de comunidades virtuais de aprendizagem. In: Barbosa, R.M. (Org.). 2005. Ambientes Virtuais de Aprendizagem. ARTMED, Porto Alegre. 